\title{
DEGENERATION OF THE PRIMARY AND SECONDARY SENSORY NEURONES AFTER TRIGEMINAL INJECTION
}

\author{
BY \\ JOHN PENMAN and MARION C. SMITH*
}

This paper comprises a clinical and pathological report of a case of tic douloureux, in which death occurred three and a half months after a successful injection of the right trigeminal nerve.

Though this form of injection has been practised for nearly $\mathbf{4 0}$ years, there is still dispute about the exact site of action of the alcohol, the changes which it produces in the trigeminal pathway, and their duration.

Chance (1920) wrote ". . . it is not known for how long in a given case the influence of the alcohol can last, nor has it been settled by post-mortem studies, I believe, just how great is the destruction of the ganglia." So far as we can discover, these words are still essentially true. Similarly, after the parallel procedure of sensory rhizotomy, only a few pathological studies have been made of the sensory root and central trigeminal pathway. Spiller and Frazier (1901) and others have made such studies in various experimental animals ; but so far as we know, the only three human cases that have been reported are those of Sjöqvist (1938).

Cavina (1932) made an ingenious investigation of the site of action of alcohol. On numerous occasions he gave a trigeminal injection and immediately proceeded to a posterior rhizotomy, having left the needle in place ; on opening the cave of Meckel he noted the position of the needle point. He was able to infer that the alcohol had the greatest effect when injected among the fibres of the sensory root just anterior to the porus trigemini.

We have discovered only two workers who describe the histology of the trigeminal ganglion and the adjacent trigeminal fibres after injection. Both found changes which might or might not have been due to the alcohol, but neither attempted to determine the site of the injection from the histological picture. Guarch (1924) described two cases of tic douloureux treated by alcoholic injection; the ganglia were extirpated after an unspecified interval and he stated that they were unaltered by the

* From tne Neurological Unit, Medical Research Council, National Hospital, Queen Square, London. injection, though he enumerated various chronic degenerative changes. He noted chiefly that the ganglion cells nearly all had dark staining nuclei, shrunken bodies and vacuolated cytoplasm; the capsular cells were said to be phagocytic. In addition the nerve fibres were grossly demyelinated. It is difficult to see how he was so sure that the alcohol had played no part in producing this degeneration. Heilmann (1929) also described a case in which a trigeminal injection had been made ; the ganglion cells showed chronic degeneration and there was demyelination of both the central and peripherat $\omega$ portions of the nerve fibres. Neither of these papers contains details of the degree of sensory disturbances produced by the injections. Without this informa $\vec{T}$ tion one cannot be sure that the alcohol came int $\mathbb{D}$ contact with any part of the trigeminal pathway. 8 등

Proof that alcohol can destroy ganglion cells an their fibres was provided by Chiasserini (1915) $\overrightarrow{0}$ Using dogs, he injected alcohol under direct visio of into the spinal posterior root ganglia and examined them histologically after various intervals; all degrees of cell and fibre destruction were found.

As to the duration of the effects of alcoholic injection on the human trigeminal nerve, the evidence for this has hitherto been clinical (Harris, 1920 ; Carmichael and Woollard, 1933).

The case described here offers some histological evidence of the effects of alcohol on the human trigeminal pathway and their probable duration.

\section{Nomenclature}

The term " Gasserian ganglion" has been used in two different senses : (1) in the older sense, based on 3 gross appearances, the ganglion is the swelling of the $\delta$ trigeminal nerve and includes all the nervous struc- $₹$ tures within the cave of Meckel ; (2) in the newer 을 histological sense it is only the band of nerve cells intervening between the three main divisions of the nerve and its sensory root. There is thus one structure which belongs in the older nomenclature to the $\sigma$ ganglion and in the newer to the sensory root; this $N$ is the aggregation of nerve-bundles between the $N$ 
cellular band and the porus trigemini ; it has long been called the plexus triangularis.

We propose to follow Ferner (1949). He uses the word ganglion in its newer and more restricted sense, replaces the term plexus triangularis by the term pars triangularis (of the sensory root), and calls the remainder of the sensory root, from porus trigemini to pons, its pars compacta.

\section{Case Report}

In June, 1945, a man, then aged 73 years, began to suffer from increasingly severe pain which was always confined to the right cheek and forehead, occurred in paroxysms lasting only a few seconds, and was often precipitated by eating, talking, washing the face or bodily exertion. In every way the pain was typical of tic douloureux. This continued until July, 1947, when because of it he was admitted to hospital. On July 25 , 1947, a full neurological examination revealed no significant abnormalities. In particular the motor, reflex, and sensory functions of both trigeminal nerves were normal. Routine radiographs of the skull were taken, also on July 25 , and reported on by Dr. James Bull as negative. The same day a right trigeminal injection was given. When the needle point seemed to be suitably placed, $0.1 \mathrm{ml}$. of procaine was injected; within one minute there was anæsthesia to firm pinpricks throughout the right trigeminal area. Next 0.5 $\mathrm{ml}$. of $90 \%$ alcohol was injected in divided doses of $0.05 \mathrm{ml}$. The needle was left in place for half an hour, after which, there being no diminution of the anæsthesia, it was withdrawn. Because of certain abnormalities found during physical examination, radiography of the chest had been performed. Dr. Bull reported that the film suggested the presence of large secondary carcinomatous deposits in both lungs.

The patient was re-examined at the second, third, fourth, sixth, and eighth weeks after injection. By late October, 1947 he had begun to be cachectic, and on November 3 he was re-admitted to hospital. During the next 12 days he was examined several more times, the last occasion being on November 13. At every examination there was anæsthesia to heavy pin-pricks throughout the right trigeminal area. The right side of the forehead and the right cheek were tested for deep pressure sense; this was quite absent. On November 15 the patient died.

Necropsy.-Twelve hours after death formol saline was injected into the cisterna magna and the head rotated so that the fluid should run over the base and anterior aspects of the brain. The necropsy, unavoidably delayed until 60 hours after death, was performed by Dr. J. N. Cumings. The base of the brain and the emerging nerves were found to be well fixed. The brain and the contents of both caves of Meckel were removed. To the naked eye there was no abnormality of the brain, ganglia, or nerves and no secondary deposits were found, though carcinomatous masses were present in the apices of both lungs. The other organs were healthy.
Preparation of Sections.-Fixation was continued in $20 \%$ formol saline for 14 days. The ganglia and attached nerve fibres were embedded by the celloidin method. The mid-brain, pons and medulla were sliced transversely, alternate slices being prepared by ordinary celloidin embedding and for staining by the Kulchitsky modification of the Weigert-Pal technique. Sections of the ganglia and fibres were cut serially at the angle which gave the greatest longitudinal and transverse diameters. The stains used on the ganglia and fibres were Ehrlich's hæmatoxylin and eosin; Anderson's iron hæmatoxylin and van Gieson's stain; Mallory's phosphotungstic acid hæmatoxylin ; thionin ; Gros' silver stain ; Loyez' myelin stain; and Gordon and Sweet's reticulin stain. Most of the sections were stained by Anderson's iron hæmatoxylin and van Gieson's method or by Gros' silver method, the other stains being used on representative sections at different levels. As a control, six normal ganglia and sensory roots were obtained at necropsies; five were embedded in paraffin and one in celloidin. These control specimens were sectioned as similarly as possible to the injected one. The paraffin preparations were cut serially, and, at intervals of 50 , sections were stained by Ehrlich's hæmatoxylin and eosin, by Anderson's iron hæmatoxylin and van Gieson's stain, and by thionin. In the celloidin preparations every tenth section was stained by Gros' silver method, and a few sections by the hæmatoxylin and van Gieson's method.

Sections from the slices of mid-brain pons and medulla, were stained by Kulchitsky's modification. of the Weigert-Pal method, Ehrlich's hæmatoxylin and eosin, thionin, Loyez' myelin stain and Gros' silver stain.

\section{Examination of Sections}

For descriptive purposes it is convenient to divide the trigeminal pathway into a peripheral and a central part. In all the figures $(a)$ denotes normal controls, and $(b)$ sections from the injected side in this case.

Peripheral Trigeminal Pathway.-The sensory root in the porus trigemini, át its point of transition from pars triangularis to pars compacta, shows very definite changes. The usual formation of approximately parallel bundles of nerve fibres is completely disorganized. There are fewer bundles than usual; many are broken up into segments and are entangled in fibro-vascular tissue which is more abundant than in the normal (Figs. 1 and 2). The very few remaining normal bundles lie near the supero-medial border of the sensory root. Except in these few bundles most of the nerve fibres show gross degeneration, with almost complete loss of myelin ; the Schwann cells are increased in number and there is a considerable leucocytic reaction (Fig. 3). The only axis cylinders persisting are fine ones, which are swollen, and the argentophil material is mainly in the form of granular detritus. The pars triangularis is very different from the normal. A few fine nerve fibre bundles run from the ganglion cells, but 


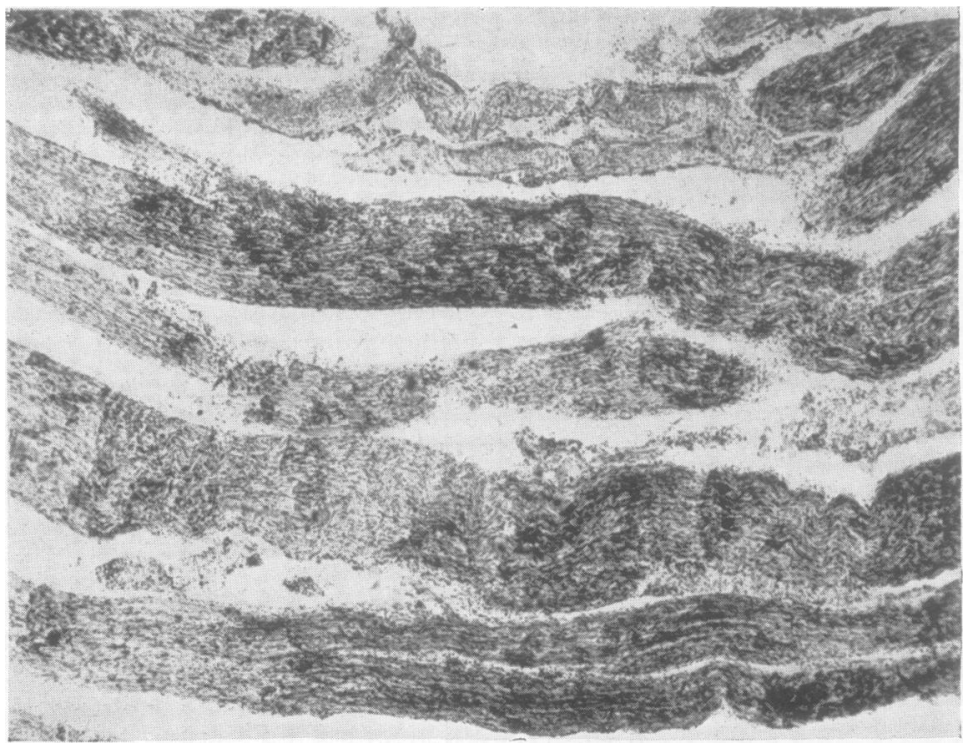

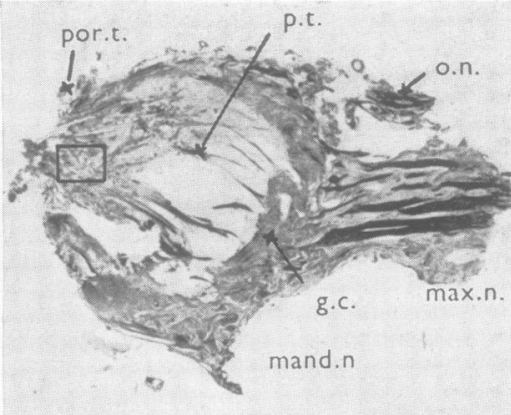

Fig. 1a.-Section of normal trigeminal ganglion and sensory root.

Fig. 1b. - Section of injected trigeminal $\frac{q}{\varphi}$ ganglion and sensory root. ( $x 2$. Anderson's iron hæmatoxylin and van Gieson's stain.)

o.n : ophthalmic division of fifth nerve ; max.n : maxillary division ; mand.n : mandibular division; p.t: pars triangularis of sensory root; por.t: $\vec{\omega}$ porus trigemini ; g.c : ganglion cells.

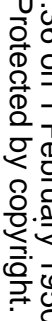

2a

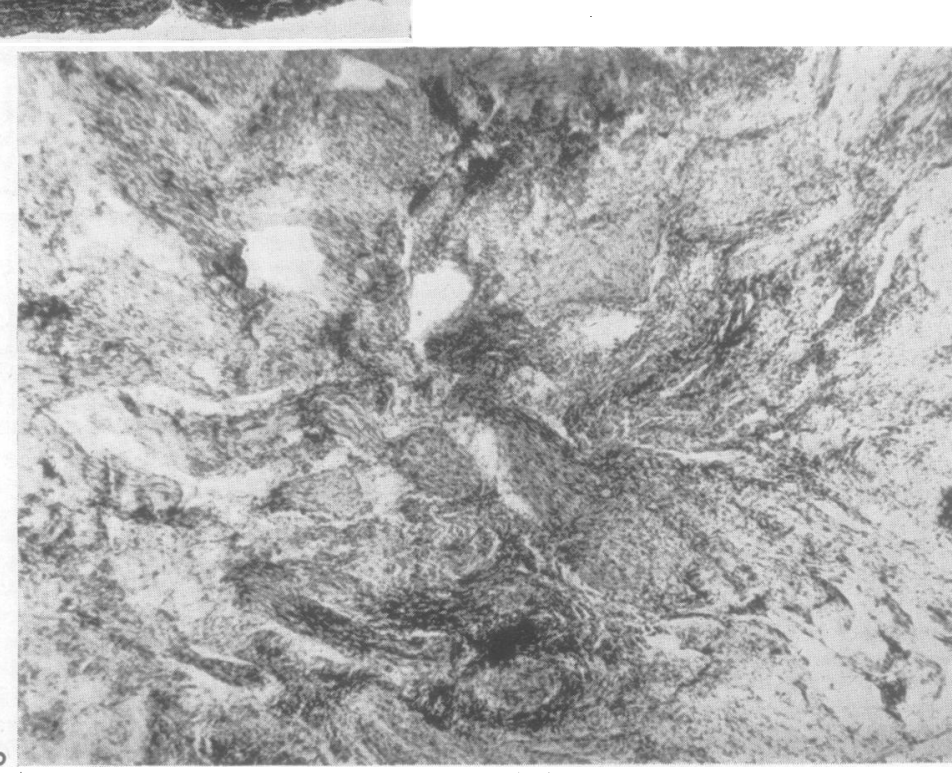

Plate I

FIG. 2a.-Area of porus trigemini in normal sensory root outlined in FIG. $1 a$ showing bundles of nerve fibres.

Fig. 2b.-Similar area in injected root, outlined in FIG. 1b, showing disorganized nerve fibres. (x 40. Anderson's iron hæmatoxylin and van Gieson's stain.) 


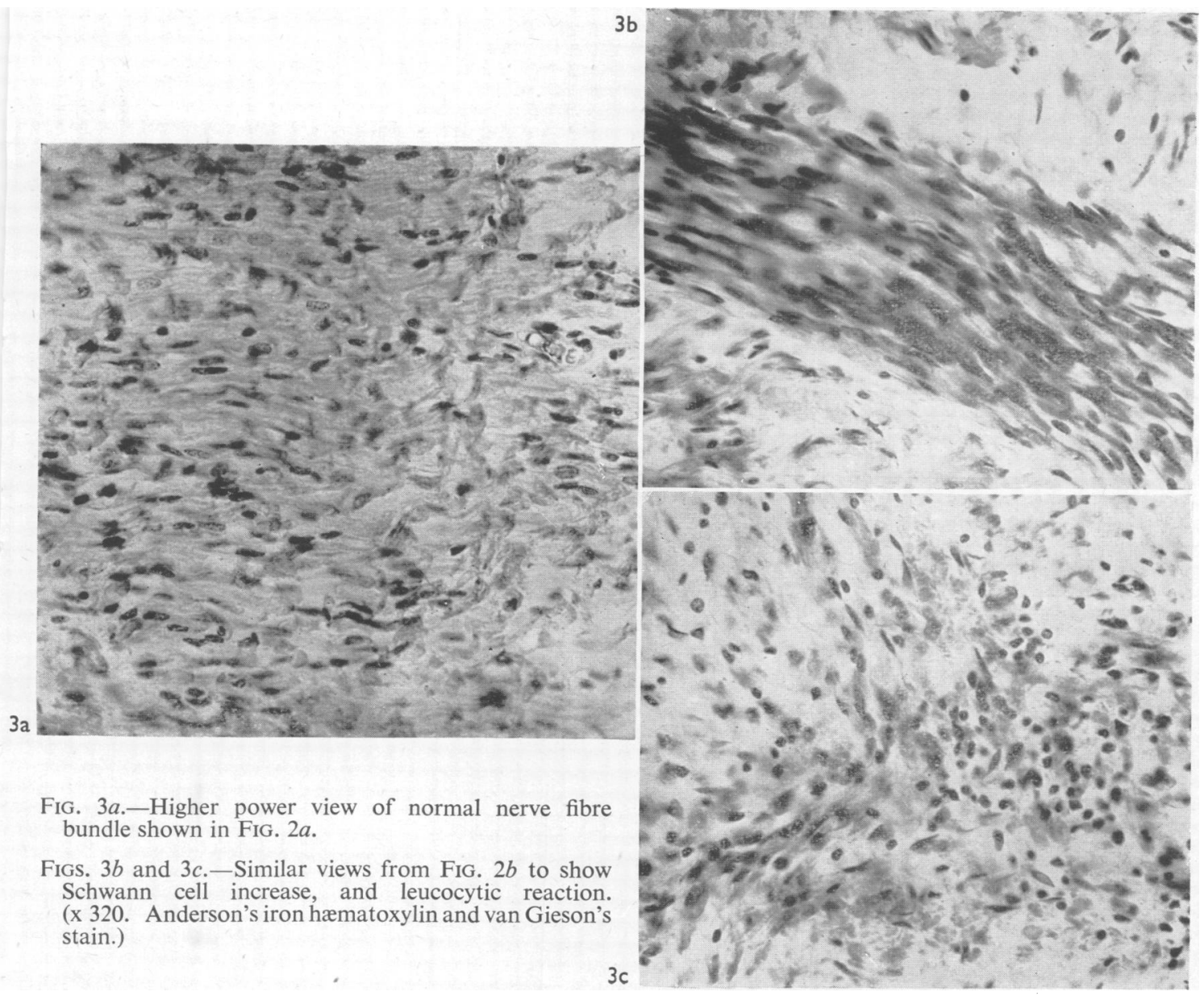

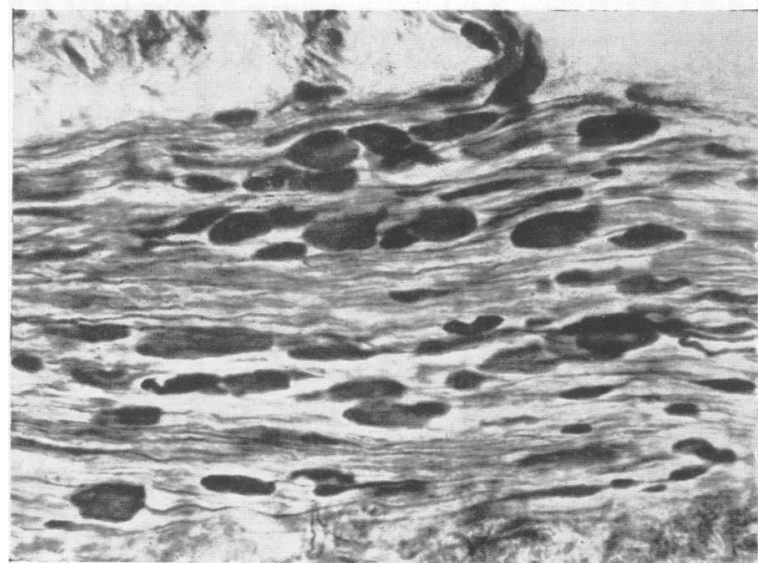

Fig. 4.-Nerve fibre bundle near the ganglion cell zone of the injected ganglion, showing large argentophil swellings. (x 200. Gros' silver stain.)

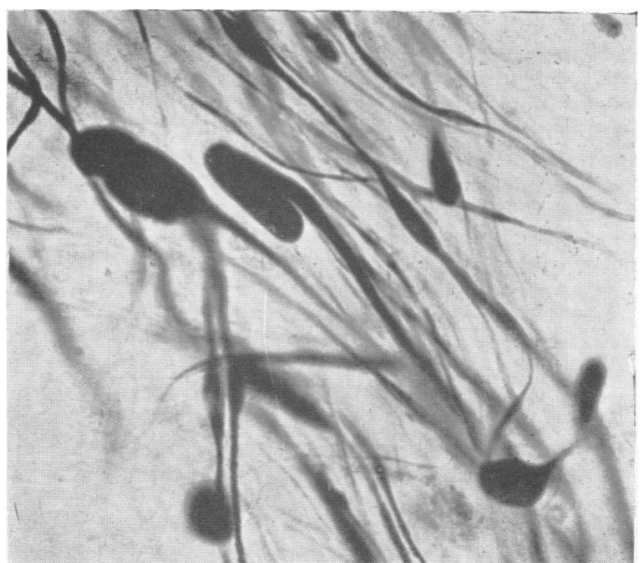

Fig. 5.-Similar area to FIG. 4. (×400. Gros' silver stain.)

Plate II 


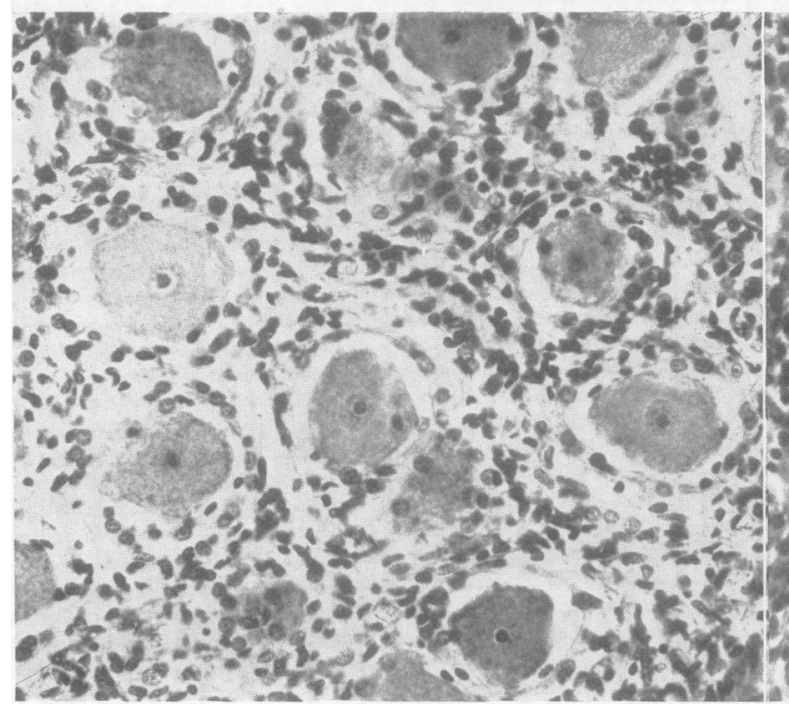

FIG. 6a.-Ganglion cells of left, normal trigeminal ganglion.

FIG. $6 b$-Ganglion cells of right injected trigeminal ganglion showing marked cellular proliferation. is $(\times 250$. Anderson's iron hæmatoxylin and van Gieson's stain.)

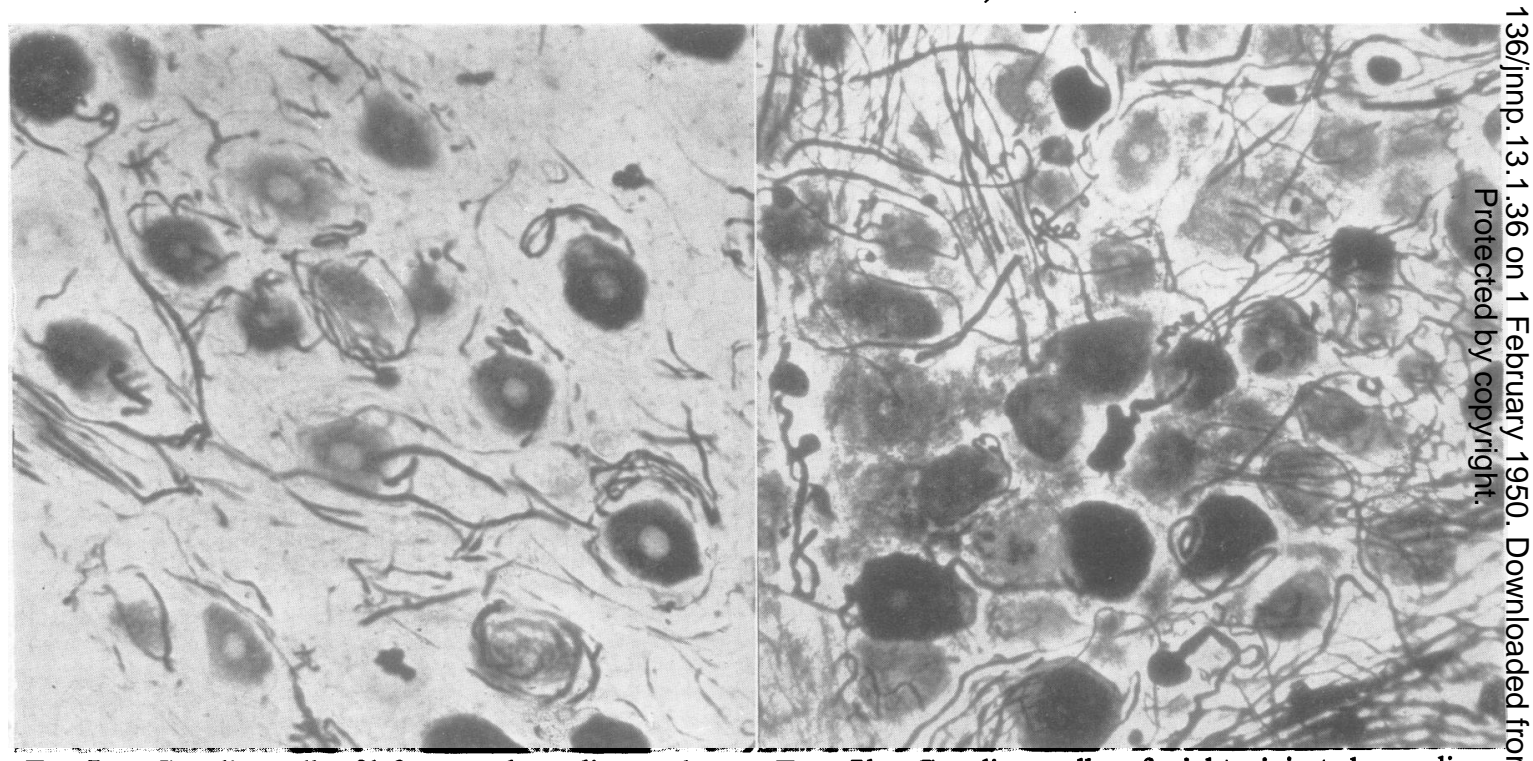

FIG. 7a.-Ganglion cells of left, normal ganglion to show condition of pericellular network and axis cylinders. Some thickenings of the processes are present.

FIG. $7 b$. - Ganglion cells of right, injected ganglion $\exists$ showing many irregular large swellings on the axis cylinders. $(\times 200$. Gros' silver stain.)
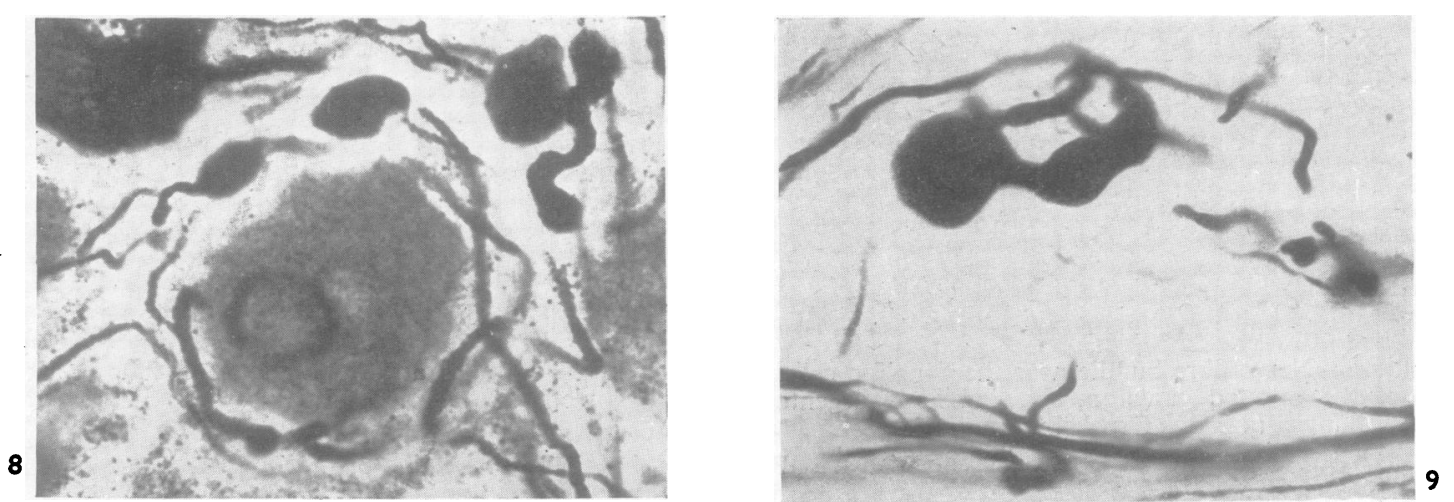

FIGs. 8 and 9.-Higher magnification of pericellular and axis cylinder swellings as shown in Fig. $7 b . \quad(\times 600$. Gros' silver stain.) 


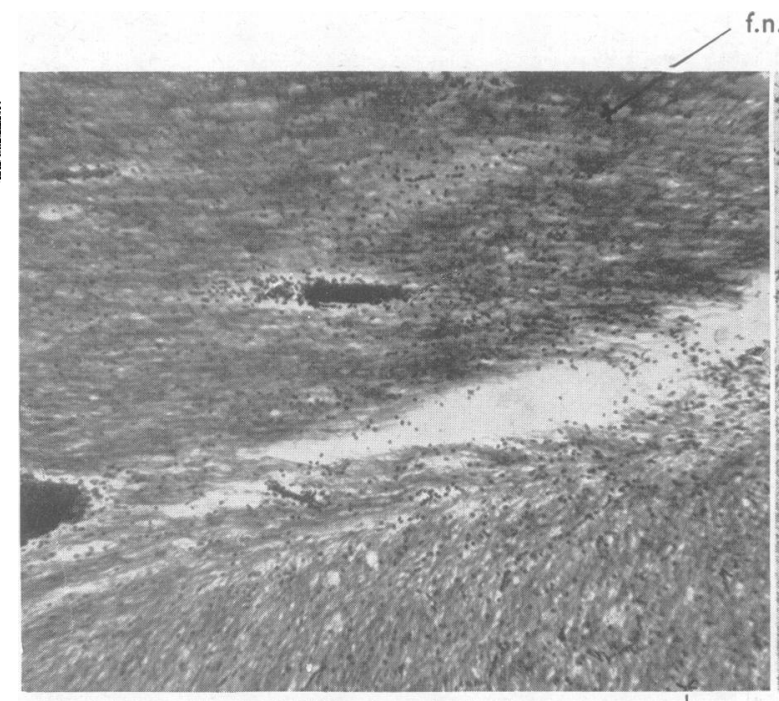

FIG. 10a.-Normal fifth nerve just after entrance into pons.

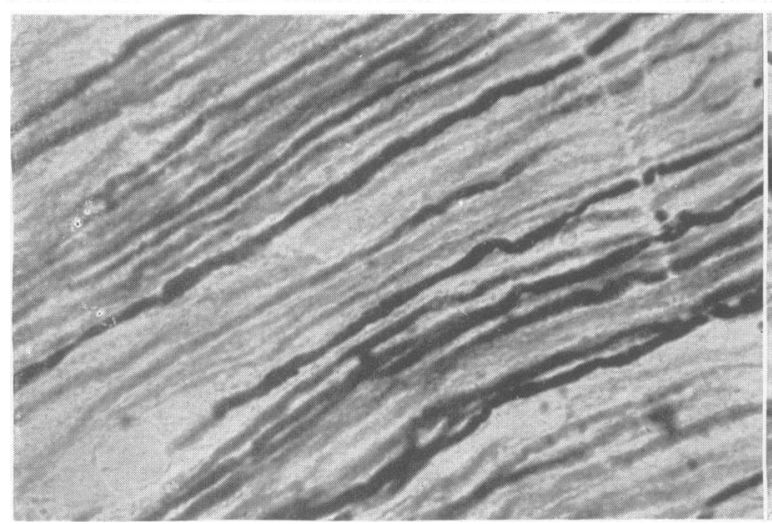

FIG. 11a.-Axis cylinders in intra-pontine part of normal fifth nerve.

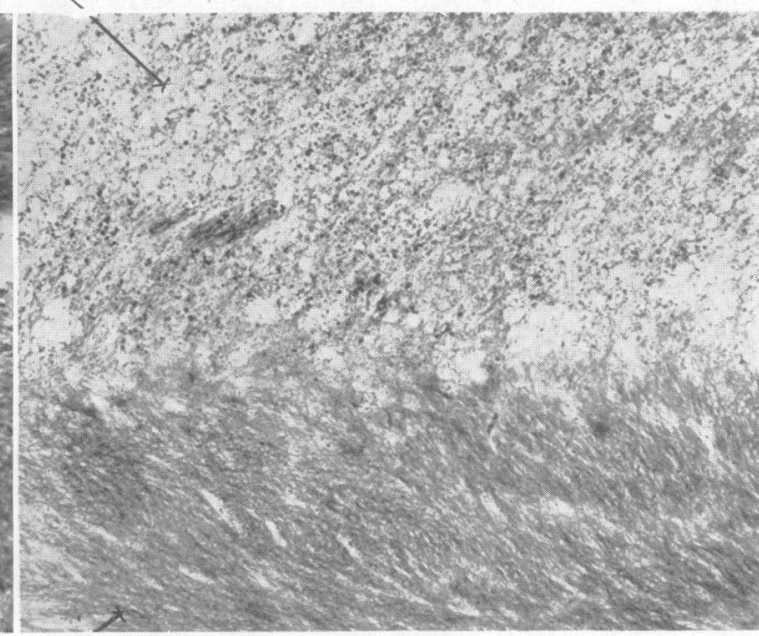

Fig. 10b.-Injected fifth nerve just after entrance into pons, showing pallor due to gross demyelination. $(\times 60$. Loyez' myelin stain. $)$ b.p.: fibres of brachium pontis ; f.n.: fifth nerve.
FIG. 11b.- Intra-pontine part of injected fifth nerve, showing loss of many axis cylinders and presence of argentophil detritus. ( $\times 350$. Gros' silver stain.)

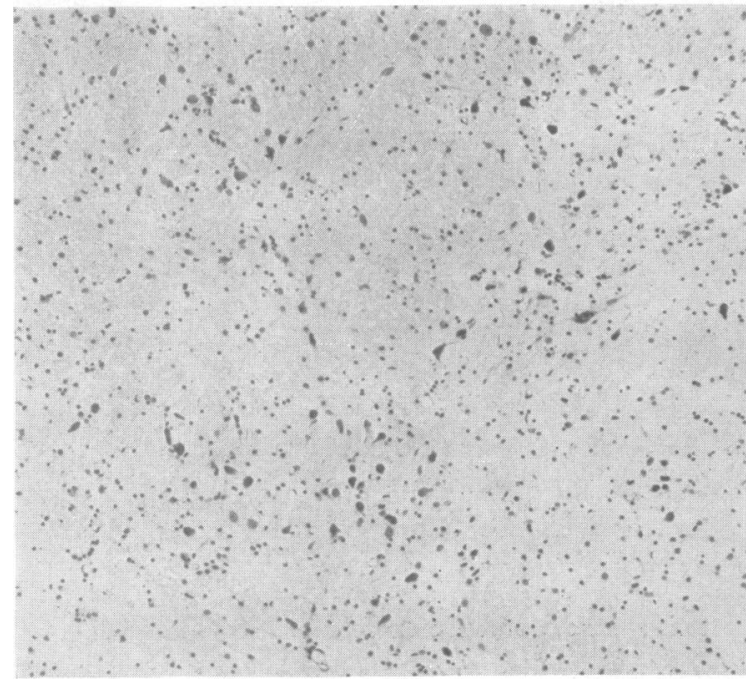

Fig. 12a.-Main sensory nucleus of normal fifth nerve.

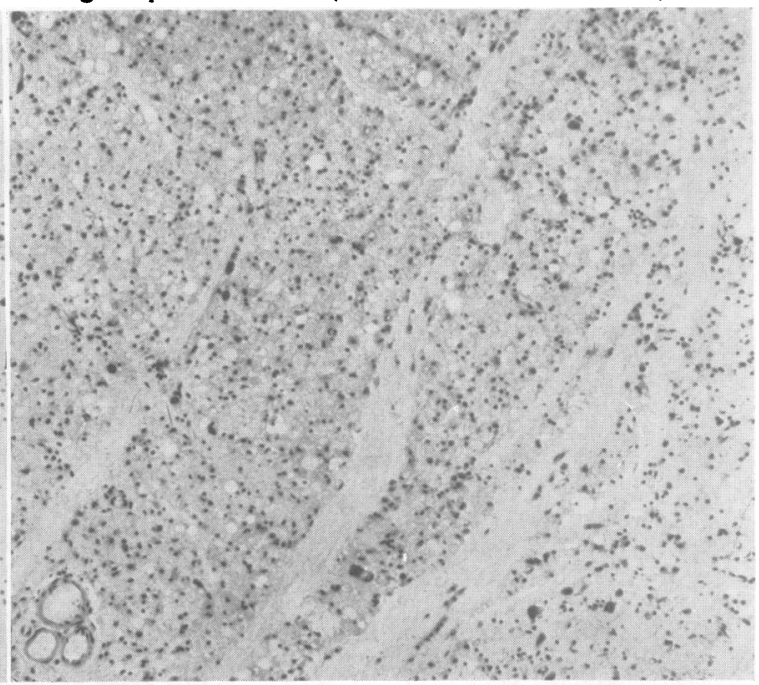

FIG. 12b.-Main sensory nucleus of injected fifth nerve, showing loss of nerve cells. There is marked microglial increase. ( $\times 80$. Thionin stain.) 


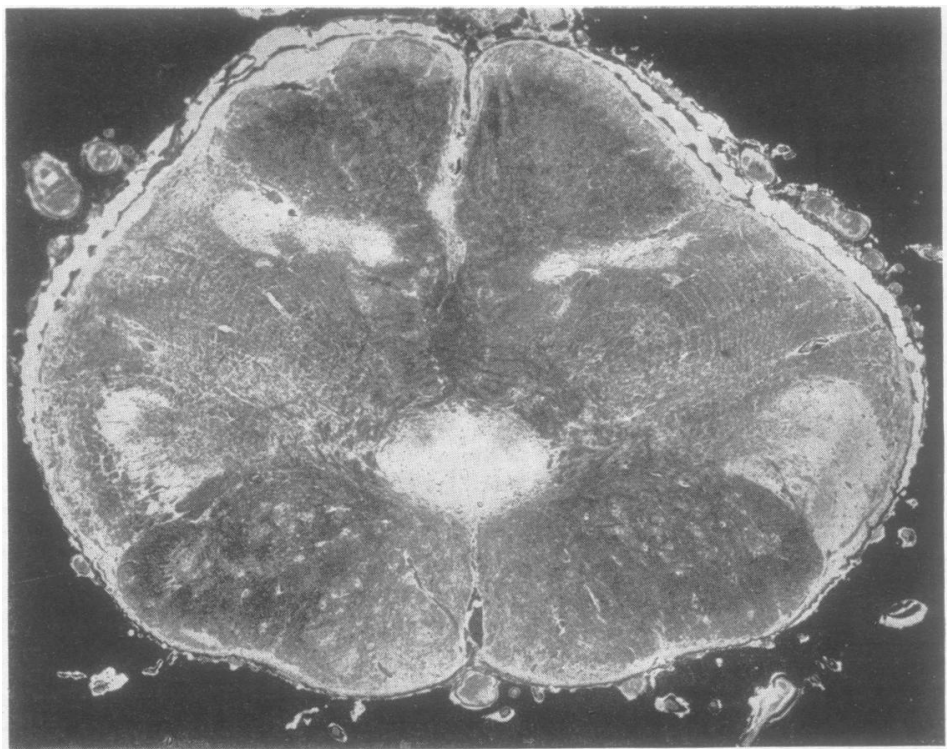

Fig. 13.-Transverse section of medulla showing loss of axis cylinders in spinal tract of fifth nerve on right, injected side, compared with left normal side. ( $\times 7$. Gros' silver stain.)

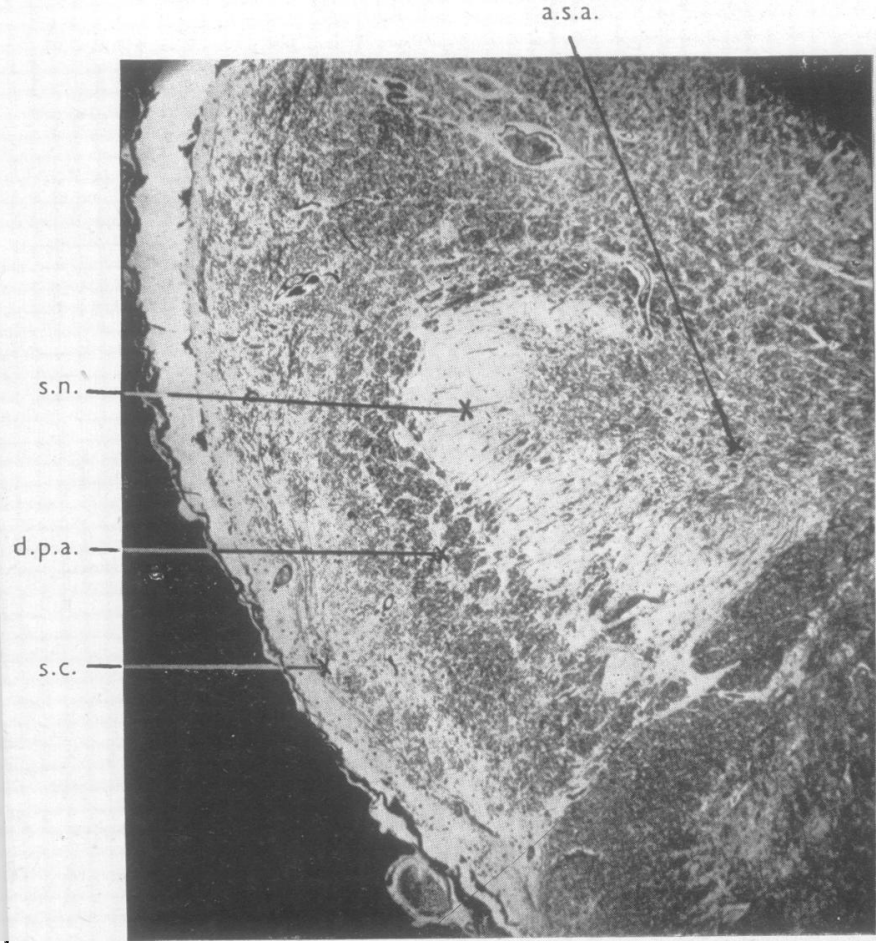

Fig. 14a.-Enlarged view of left, normal tract shown in FIG. 13.

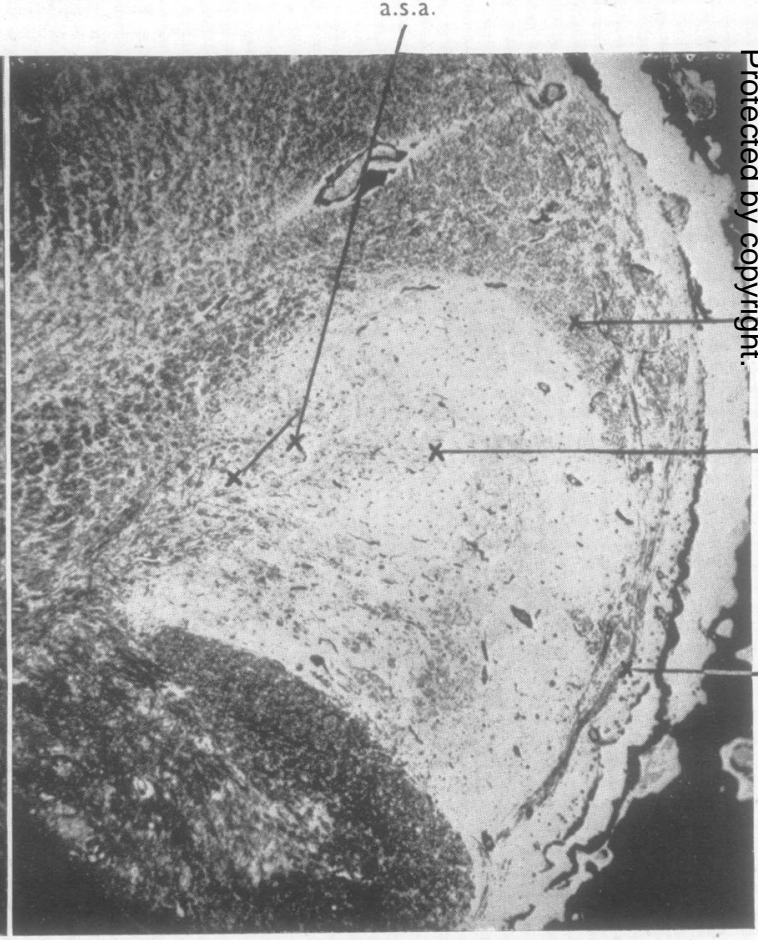

Fig. 14b.-Similar view of right, injected tract, showing loss of descending axis cylinders of spinal tract. There is also a loss of secondary ascending axis cylinders in the hilum of the nucleus. $(\times 25$. Gros' silver stain.)

d.p.a : descending primary axons of fifth nerve; s.n : region of cells of spinal nucleus; a.s.a : ascending secondary axons of fifth nerve; n.a : few normal axons; s.c: dorsal spino-cerebellar axons. 


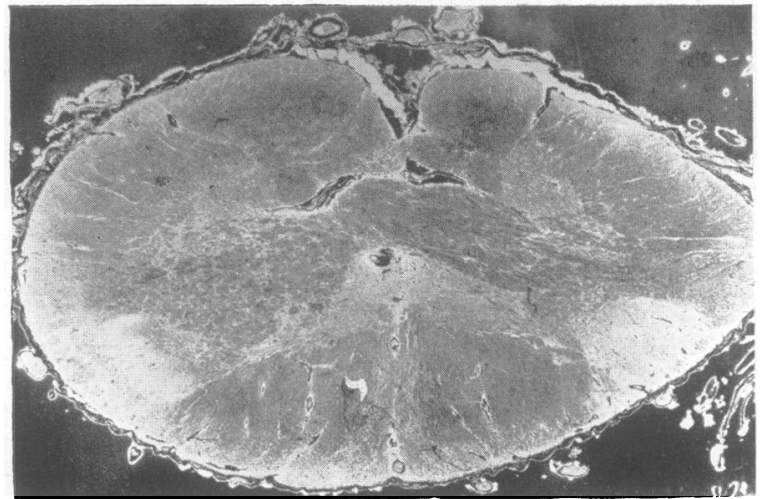

Fig. 15.-Transverse section of medulla at region of pyramidal decussation. As in FIG. 12, loss of descending and of ascending axons in right, spinal tract of fifth nerve, seen. ( $\times 7$. Gros' silver stain.)

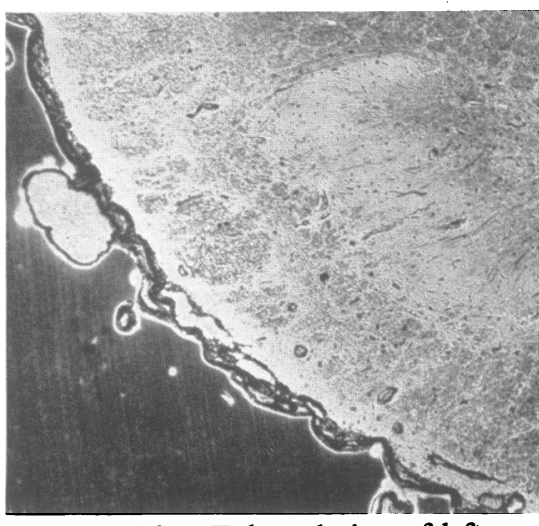

FIG. 16a.-Enlarged view of left normal tract.

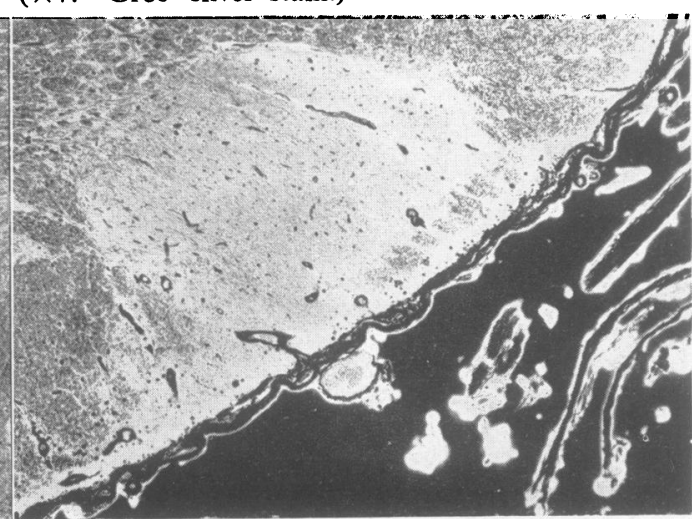

Fig. 16b.-Similar view of right injected tract, showing absence of descending and ascending axons, as in FIg. 14b. No intact descending axons present at this level. $(\times 25$. Gros' silver stain. $)$

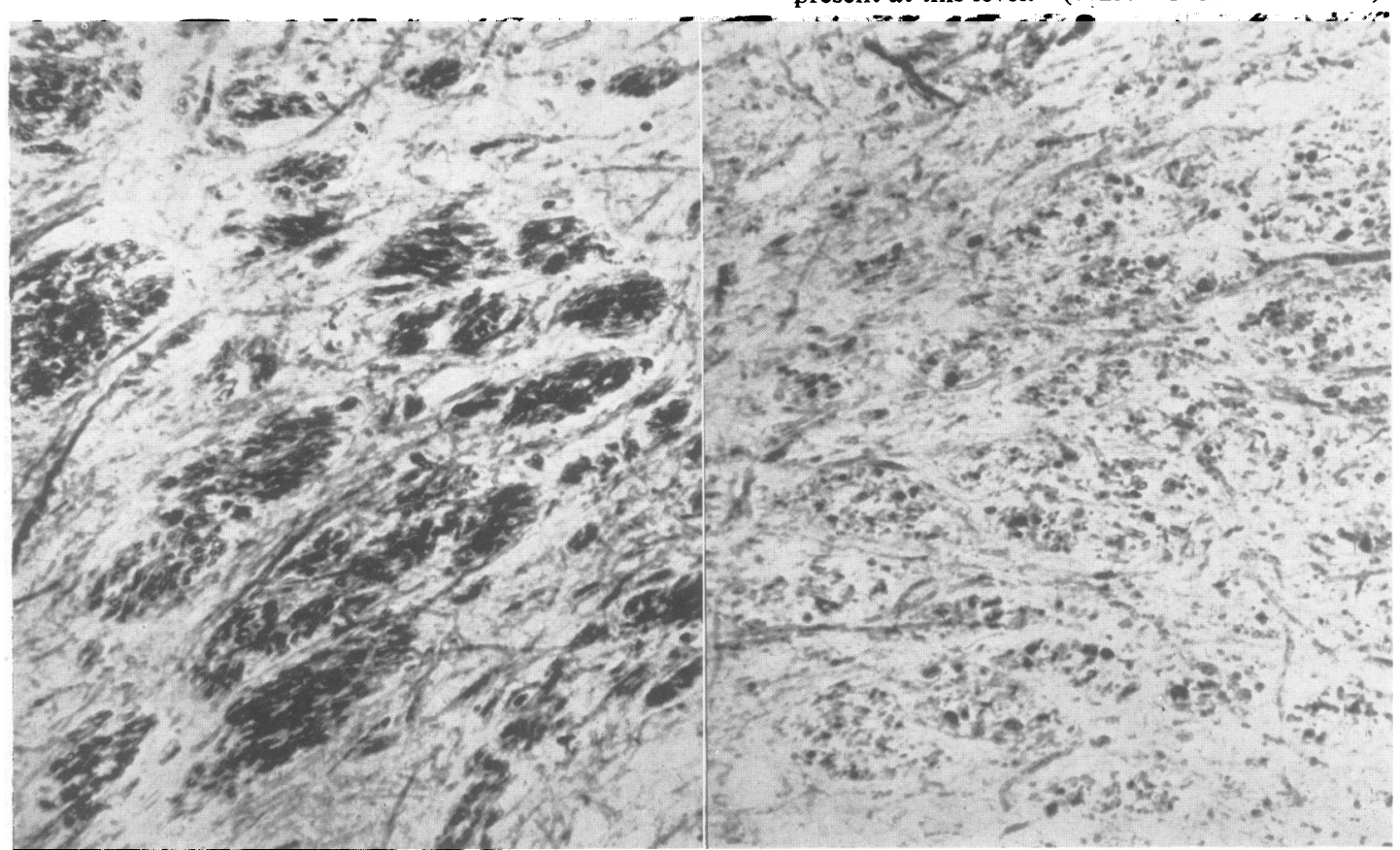

FIG. 17a.-Secondary ascending trigeminal tract on normal side, at mid-medullary level.
FIG. 17b.- Similar area on injected side, showing loss of fibres. ( $\times 150$. Weigert-Pal stain.) 


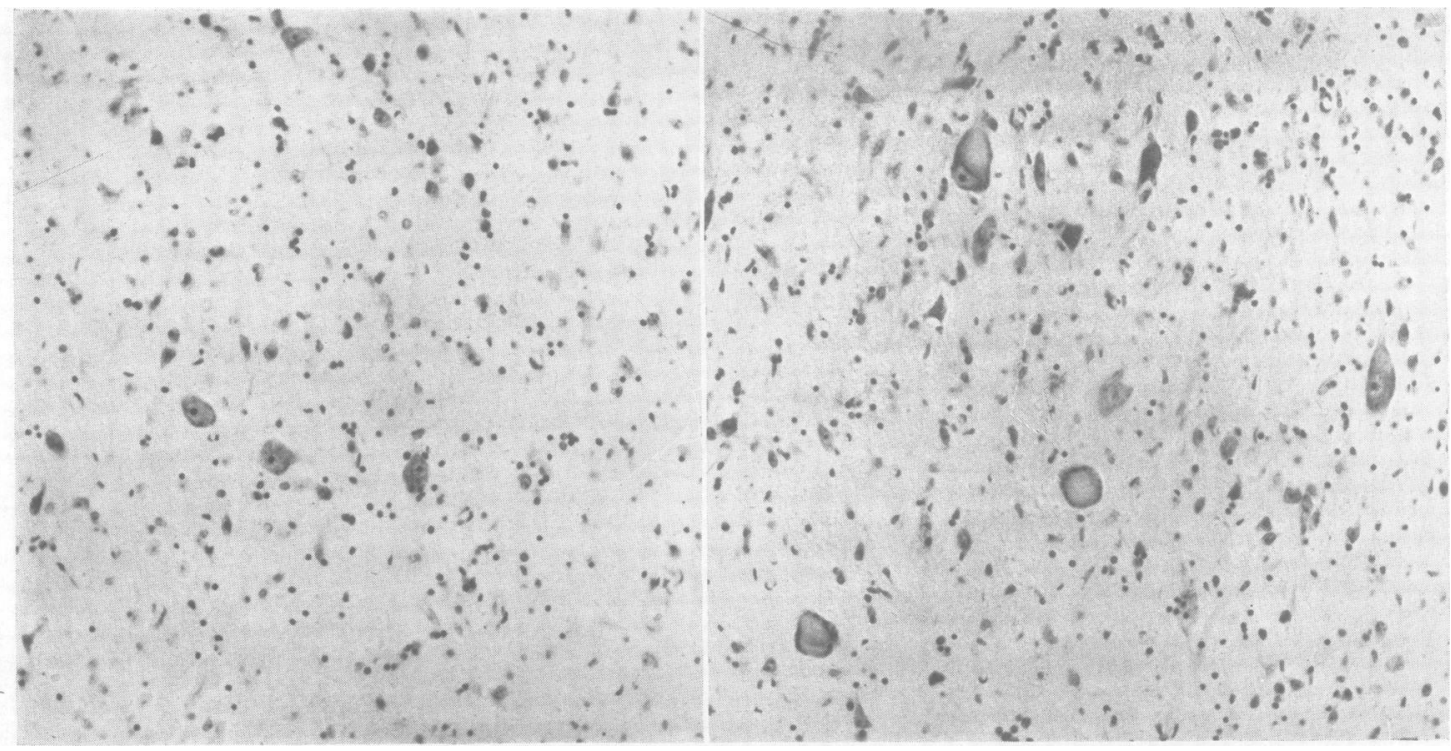

Fig. 18a.-Spinal nucleus of normal fifth nerve.

FIG. 18b.-Spinal nucleus of injected fifth nerve showing chromatolytic neurones. $(\times 200$. Thionin stain.)

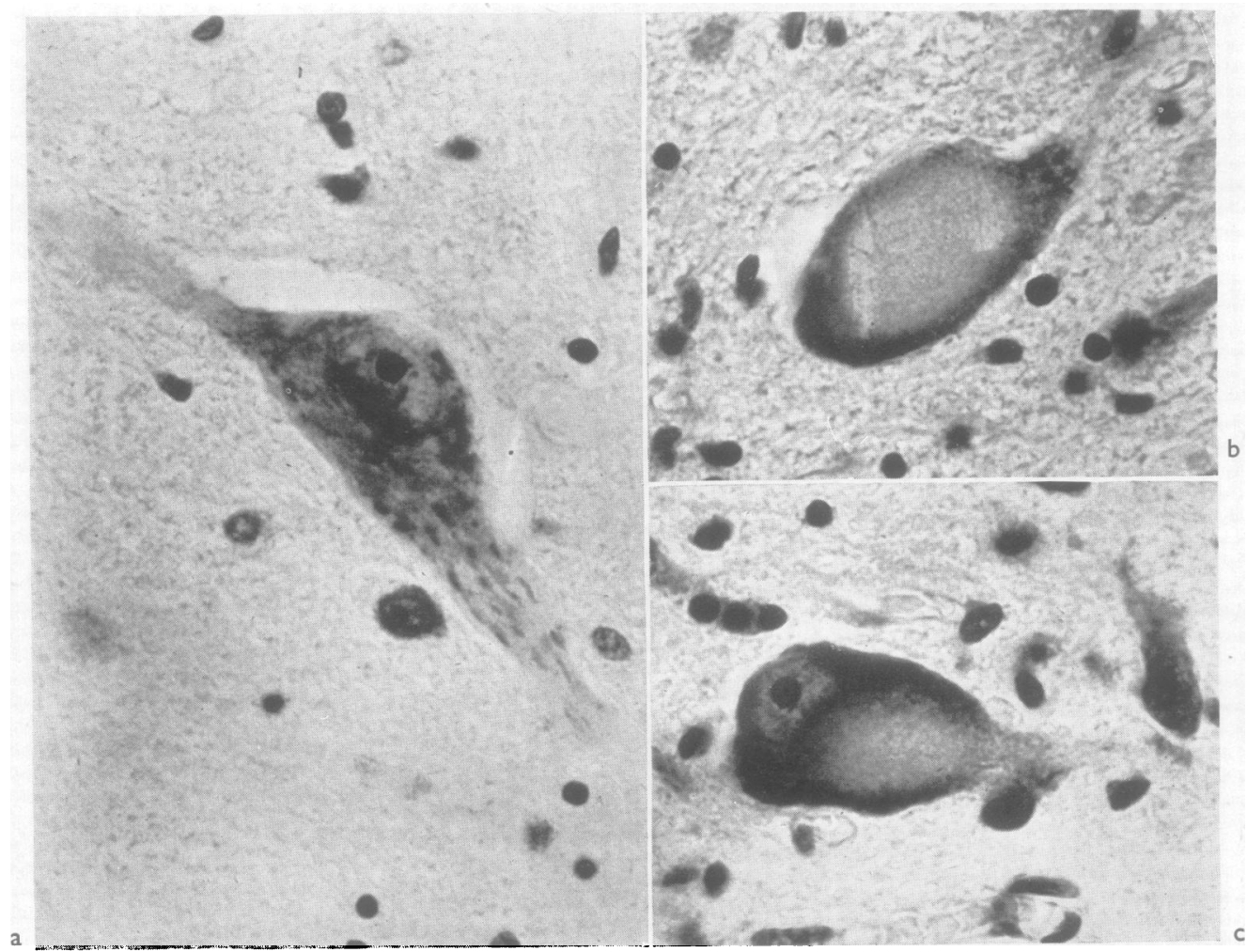

FIG. 19a.-Medium-sized neurone from normal FIGS. $19 b$ and c.-Medium-sized neurones spinal nucleus. from spinal nucleus of injected side, showing swollen cell bodies, eccentric or absent nuclei, and chromatolysis. 
they amount to only a fraction of the usual number (Fig. 1). The myelin staining of these fibres is more definite near the ganglion cells and fades off near the porus trigemini, as already described. There is a great increase in cellularity. A few normal axis cylinders are present, but most of them are swollen and many end centrally in bulbous enlargements (Figs. 4 and 5). Fine silver-staining debris in clumps appears to represent completely degenerated fibre bundles. Between the bundles is a fine fibro-vascular network, continuous with the fibro-vascular tissue in the region of the porus trigemini. In some regions there seem to be spaces containing no tissue at all. Although the plane of the section may contribute to this appearance it must be partly due to actual loss of tissue, for the walls enclosing the spaces have a smooth fibrous lining; small clumps of argentophil material are seen round the spaces. This apparent loss of tissue is most marked near the infero-lateral border in the superficial sections, and the supero-medial border in the deep sections. It is possible that necrotic tissue from the spaces may have escaped during the fixing and embedding. The band of ganglion cells is of varying and irregular width exceeding the limits of irregularity seen in the normal (Ferner, 1940). There is evidence of actual cell loss in the part of the ganglion cell band next to the pars triangularis; here there are residual nodules, some still containing fragments of the dead neurones. In the hæmatoxylin and van Gieson and in the thionin preparations there is a generalized increase in non-neuronal cellularity in the ganglion cell band, particularly marked on the side next to the pars triangularis. Many of the ganglion cells are normal in appearance, within the limits of senile changes (Ramón y Cajal, 1928 ; Opalski, 1930 ; de Castro, 1933 ; Truex, 1940 ; Andrew, 1941). In scattered areas there is marked cellular proliferation and slight loss of neurones (Fig. 6). The preparations stained by Gros' silver method show thickened pericellular networks and many irregular processes arising from cells; these processes have swollen bulbous ends (Fig. 7). Similar structures are scattered among the cells (Figs. 8 and .9). The divisions of the nerve normally consist of nerve bundles embedded in fibrous tissue ; no increase in this tissue can be seen. Some minor changes are present in the fibres of the ophthalmic and maxillary divisions ; these consist of occasional disintegration of the sheaths, and of varicosities in the axis cylinders without break in the continuity. In the mandibular division these changes are rather more marked; here there is a greater loss of myelin, and bulbous swellings are present on the axis cylinders. The changes are not suggestive of gross damage, and may be, at least in part, artefacts.
Central Trigeminal Pathway.-The fifth nerve root as it enters and traverses the pons is grossly disintegrated. The myelin sheaths are almost completely disrupted, and the myelin staining material is present in irregular clumps and as granular detritus (Fig. 10). There are very few axis cylinders of normal appearance; the rest are represented only by argentophil debris (Fig. 11). The main sensory nucleus, consisting normally of rather small nerve cells, exhibits here a definite reduction of the number of the neurones ; amongst the remainder many are dark staining and shrunken. The degenerating fibre tracts show a marked microglial reaction, and in the sensory nucleus this increased cellularity masks to some extent the loss of nerve cells (Fig. 12). The degeneration seen in the intra-pontine part of the fifth nerve is present throughout the descending tract, and is clearly seen in Gros', Loyez, and Weigert-Pal preparations (Figs. 13, 14, 15, and 16). In the medulla, that is, nearer the termination of the tract, the degeneration is absolute. The only fibres which remain intact at this level are a few situated most anteriorly ; these must be the same fibres as those which were found intact near the superomedial border of the sensory root, and it is not improbable that they belong to the ophthalmic division. Very definite changes are present in the spinal nucleus. In this nucleus the neurones are of two types, medium- and small-celled. About twothirds of the medium-sized neurones are swollen, the nucleus is absent or displaced to one side of the cell, and there is moderate chromatolysis (Figs. 18 and 19). There is evidence of severe damage in a few of the smaller neurones, which are shrunken with dark staining nuclei. Clumps of microglial cells are seen, suggesting neuronophagia of completely degenerated neurohes.

Authorities are agreed that the secondary spinal fibres run in the hilum of the nucleus. On the injected side in this case there is definite pallor of the secondary tract in both myelin and axis cylinder preparations. The fibres of this tract run in small bundles, which in this case have lost many of their fibres (Figs. 13-17). No pallor could be detected where the fibres cross in the secondary tract ; this, however, is not surprising as the decussation is so gradual that the absence of a few fibres would not be demonstrable by the negative stains used.

The mesencephalic nucleus and the motor nucleus show no alteration from the normal.

\section{Summary of Histological Findings}

In the trigeminal nerve the site of maximum tissue destruction is the pars triangularis of the sensory root, where there is a great loss of fibre bundles, and degenerative changes in the remaining fibres. Fibro- 
vascular tissue is normally present between the bundles; here it is much increased in amount. There is no extensive loss of neurones in the ganglion. Some neurones adjacent to the pars triangularis appear to be completely destroyed ; a few degenerating cells with marked non-neuronal cellular reaction are scattered among healthy neurones. There is thickening of peri-cellular plexuses; irregular clumps of argentophil material are present between and around the nerve cells, and generalized cell proliferation is seen. Many axis cylinders arising from the neurones end centrally in bulbous swellings. Within the central nervous system, the main sensory and the descending trigeminal tracts are degenerated, with loss of myelin sheaths and axis cylinders; the only fibres surviving in these tracts are a few presumably from the ophthalmic area. The mesencephalic nucleus is normal. There is evidence of degeneration in many of the nerve cells of the main sensory and spinal nuclei, and considerable loss of secondary fibres. Very minor degrees of variation from the normal are present in the peripheral divisions of the nerve.

\section{Discussion}

The injection of alcohol has resulted in very gross, probably irreversible degeneration of the nerve bundles in the sensory root. It appears also to have caused complete destruction of some ganglion cells adjacent to the pars triangularis; probably these were the only cells directly affected by the alcohol. On the whole, the changes in the neurones, their production of thickened processes, and any minor alterations in the peripheral divisions of the axons are probably of a secondary nature, resulting from damage to the central parts of the axis cylinders. The injection of alcohol was made into the pars triangularis rather nearer to the pars compacta than to the ganglion.

The destruction or damage of the fibre bundles in the sensory root has resulted in almost total degeneration of the nerve tract within the pons and throughout its course as the spinal tract. The degenerative changes of the secondary neurones in the main sensory nucleus and in the spinal nucleus, and of a large proportion of some fibres from these cells most probably indicate a trans-synaptic degeneration. After section of the sensory root (Spiller and Frazier, 1901 ; Sjöqvist, 1938), or section of the descending spinal tract (Erskine and Rowbotham, 1949), degeneration of the descending fibres of the primary neurones has been described; so far as we know, this is the first time that the secondary neurones of the trigeminal tract have been shown to undergo trans-synaptic degeneration, though its occurrence in certain other tracts has been proven.

The mesencephalic root is unaltered as would be expected, for the mesencephalic cells are the primary neurones (Carmichael and Woollard, 1933); any damage to their centrifugal fibres in the sensory root need therefore cause no permanent changes in these cells. Apart from these fibres and the very few others escaping unaffected at the time of injection, there is an irreversible loss of the intracerebral sensory part of the fifth nerve. Even if new centripetal fibres were to grow from the neurones of the ganglion, they would be unable to extend beyond the surface of the pons (Schäfer, 1913 ; Spielmeyer, 1922 ; Ramón y Cajal, 1928).

\section{Summary}

The histological changes after an alcoholic trigeminal injection are reported. They consisted of degeneration of nerve fibres in the sensory root and throughout the tract of the fifth cranial nerve.

Evidence is presented for a trans-synaptic degeneration in the main sensory and spinal nuclei.

We wish to thank Dr. J. G. Greenfield and Dr. E. A. Carmichael for advice and criticism of this paper ; Mr. Wylie McKissock for clinical facilities kindly provided at his neurological unit; Dr. J. N. Cumings for his kindness in performing the necropsy for us ; Dr. James Bull for radiological reports; and Dr. Denis Williams for referring the patient to one of us for injection. We also gratefully acknowledge our debt to Miss Vera Burgess and Miss Kathleen Harrison for their technical assistance. The credit for the microphotographs thanks.

\section{REFERENCES}

Andrew, W. (1941). J. Anat., Lond., 75, 406.

Carmichael, E. A., and Woollard, H. H. (1933). Brain, 56, 109.

Castro, F. de (1932). “ Cytology and Cellular Pathology of the Nervous System," edited by W. Penfield. Hoeber, New York. Vol. I, p. 93.

Cavina, C. (1932). Riv. ital. Stomatol. ,1, 3.

Chance, B. (1920). Arch. Ophthal., N.Y., 49, 621.

Chiasserini, A. (1915). Policlinico, sez. chir., 22, 48, $96,138,175$.

Erskine, C. A., and Rowbotham, G. F. (1949). Arch. Neurol. Psychiat., Chicago, 62, 493.

Ferner, H. (1940). Z. Anat. EntwGesch., 110, 391.

Guarch, F. S. (1924). Virchows Arch., 249, 495.

Harris, W. (1920). Clinical Section, Proc. R. Soc. Med., $13,62$.

Heilmann, P. (1929). Virchows Arch., 272, 753.

Opalski, A. (1930). Z. ges. Neurol. Psychiat., 124, 383.

Ramón y Cajal, S. (1928). "Degeneration and Regeneration oi the Nervous System." Oxford University Press, London. Vol. II, p. 397 and 509.

Schäfer, E. A. (1912). "Quain's Elements of Anatomy", Eleventh Edition. Longmans and Green, London. Vol. II, Part I.

Sjöqvist, O. (1938). Acta Psychiat., Kbh., Supplement No. 17.

Spielmeyer, W. (1922). "Histopathologie des Nervensystems." Springer, Berlin. P. 455.

Spiller, W. G., and Frazier, C. H. (1901). Philad. med. J., 8, 1039.

Truex, R. C. (1940). Amer. J. Path., 16, 255. 